\title{
Prevalence of Obesity and Correlated Hypertension and Hyperglycaemia Status among Participants of a Health Screening Programme in Inanam Sub-district, Kota Kinabalu, Sabah, Malaysia
}

\author{
Khairul Anwar Zarkasi1, Nur Zuliani Ramli1*, Vennila Gopal'1, Sadia Choudhury Shimmi1', Anne Lolita Miranda², \\ Wan Salman Wan Saudi', Caroline Sunggip'1
}

${ }^{1}$ Department of Biomedical Sciences and Therapeutics, Faculty of Medicine and Health Sciences, Universiti Malaysia Sabah,

Kota Kinabalu, Sabah, Malaysia

2 Pusat Rawatan Warga UMS,

Hospital Universiti Malaysia Sabah,

Faculty of Medicine and Health Sciences,

Universiti Malaysia Sabah,

Kota Kinabalu, Sabah, Malaysia

\section{*Corresponding author's email: nurzuliani@ums.edu.my}

Received: 14 November 2019

Accepted: 18 December 2019

Keywords:

general obesity, central obesity, high blood pressure, high capillary blood glucose, rural health

\section{ABSTRACT}

Obesity is a known risk factor for noncommunicable diseases, including hypertension and diabetes mellitus, with Malaysia having the highest prevalence of obesity among Southeast Asian countries. Additionally, the delivery of medical services to the rural communities remains challenging despite efforts to increase accessibilities to the healthcare facilities. Therefore, regular health screening programmes specifically aiming at these communities are necessary for early diagnosis and intervention to prevent complications while improving the patients' quality of life. A health screening programme was conducted in a sub-district of Kota Kinabalu, Sabah, Malaysia, where $\mathbf{5 0}$ participants were examined for general obesity based on body mass index (BMI) together with central obesity according to waist circumference (WC) and waist-to-hip ratio (WHR). Bioelectrical impedance analysis was performed to estimate body fat percentage (fat $\%$ ) and body fat mass, along with the measurement of systolic blood pressure (SBP), diastolic blood pressure (DBP), and capillary blood glucose. The median age of the participants was $\mathbf{3 9 . 5 0}$ years. The prevalence of general obesity, central obesity based on WC and WHR, hypertension, and hyperglycaemia was $\mathbf{2 8} \%, \mathbf{7 8} \%, \mathbf{7 4} \%, \mathbf{2 4 \%}$, and $20 \%$, respectively. Both fat $\%$ and fat mass had positive correlations to the BMI (fat\%: $r=0.656, p=0.001$; fat mass: $r=0.868, p=0.001$ ) and WC (fat $\%: r=0.505, p$ $=0.001$; fat mass: $r=0.761, p=0.001)$. DBP had positive correlations with the BMI $(r=0.390$, $p=0.005)$, WC $(r=0.467, p=0.001)$, and WHR $(r=0.331, \mathrm{p}=0.019)$, while SBP had a positive correlation only with WC ( $r=0.341, p=0.015)$. Conversely, capillary blood glucose had no 
significant correlation with either BMI, WC, or WHR. The higher prevalence of central obesity among participants of the health screening program compared to the national level should raise concern among the healthcare providers regarding the future risk for hypertension and hyperglycaemia in this community.

\section{INTRODUCTION}

Since the last two decades, obesity has been regarded as a global epidemic ${ }^{1}$. According to the World Health Organization, 650 million or $13 \%$ of the total world population is obese in 20192. Among the Southeast Asian countries, Malaysia has the highest prevalence of obesity (15.1\%), followed by Brunei (14.1\%), and Thailand (10.0\%) while the least obese nations include Vietnam, Timor-Leste, and Cambodia $(2.1 \%, 3.8 \% \text {, and } 3.9 \% \text {, respectively })^{3,4}$. Obesity is the result of an imbalance between energy intake and expenditure which is stored as body fats ${ }^{5}$. Increased in adiposity results in lowgrade inflammation, insulin resistance, and activation of the sympathetic nervous system that ultimately lead to diabetes mellitus and hypertension ${ }^{6-8}$. Therefore, targeting obesity through weight reduction, active lifestyle, as well as healthier eating habits remain the mainstay of treatment for these diseases ${ }^{9}$.

Hypertension and diabetes mellitus, if left undetected, could lead to many complications. They increase the risk for diseases such as myocardial infarction, stroke, retinopathy, and nephropathy ${ }^{10,11}$ that may require hospital admission with prescriptions of multiple types of medications. Since healthcare cost in Malaysia is heavily subsidized, especially in the public sector ${ }^{12}$, treating patients with diabetes and hypertension with several complications would increase the economic burden to the nation. Moreover, hospitalization could potentially cause loss of income and reduces the productivity of the individual ${ }^{13}$. Thus, early detection of the diseases by screening programme as secondary prevention and health intervention is imperative not only to reduce the cost of treatment but also to prevent complications and sustain the patients' quality of life.

Delivery of healthcare services to the rural regions remain challenging despite efforts by the authority to increase accessibility to the health facilities ${ }^{14}$. The geographical areas, education level, as well as the socioeconomic status of the community, could influence the access to the health facilities. For instance, the health-seeking attitude towards mental health among the rural community in the North-western island of Penang was $85.4 \%$ although a majority of the respondents had an education level of only up to secondary school ${ }^{15}$. Additionally, the diabetic patients residing in a rural area of Tanjong Karang, Selangor, had high appropriate health-seeking behaviour reported at $85.9 \%{ }^{16}$. This was contrasted with the rural coastal community of Eastern Sabah where a vast majority of the respondents were living in hardcore poverty with almost half having either primary or no formal education at all ${ }^{17}$. A large proportion of this community did not have their blood pressure, blood lipid, and fasting blood glucose checked for the preceding 12 months. As a result, more than three-quarters of the respondents who were incidentally found to have elevated readings of these parameters had never been diagnosed with hypertension, hypercholesterolaemia, or diabetes mellitus by any medical personnel.

These facts delineate the importance of conducting regular health screening in rural regions. Therefore, the program aimed to determine the prevalence of obesity, hypertension, and hyperglycaemia among the Inanam sub-district community of Kota Kinabalu, Sabah, Malaysia.

\section{MATERIALS AND METHODS}

The health screening programme took place on 27 April 2019 at the Inanam sub-district of Kota Kinabalu, Sabah, Malaysia. It has a 
total population of 3,604 comprising the Bumiputera (71.0\%), non-Bumiputera (20.3\%), and non-citizen $(8.7 \%)^{18}$. In this report, all the individuals $(n=50)$ aged 18 years and above who participated in the health screening activities were included.

\section{Anthropometry}

The participants were instructed to stand barefooted on the weighing scale (SECA', Hamburg, Germany) while on loose, light clothing for the weighing procedure. Height was measured by placing the stadiometer plate (SECA', Hamburg, Germany) over the participants' heads while they were standing with a straight back. Body mass index (BMI) was calculated using the formula, $\mathrm{BMI}=$ weight $(\mathrm{kg}) \div$ height squared $\left(\mathrm{m}^{2}\right)$. By adopting the World Health Organization International Classification for Asian Population, participants were classified either as non-obese or obese based on the cut-off points of $\leq 27.4 \mathrm{~kg} / \mathrm{m}^{2}$ and $\geq 27.5 \mathrm{~kg} / \mathrm{m}^{2}$, respectively ${ }^{19}$.

Waist circumference (WC) was measured with participants who were at tidal expiration by wrapping a non-extensible measuring tape horizontally around the abdomen between the lowest border of the rib cage and the upper border of iliac crest ${ }^{20}$. Hip circumference (HC) measurement was taken at the widest part of the hip over the femoral greater trochanter ${ }^{21}$. Participants were classified as centrally obese when the WC was $\geq 90 \mathrm{~cm}$ and $\geq 80 \mathrm{~cm}$ for males and females, respectively. Waist-to-hip (WHR) ratio was calculated using the formula, WHR $=$ WC $\div$ HC. Participants with WHR $>0.9$ for males and $>0.8$ for females were considered as centrally obese. Criteria for central obesity based on measurement of WC and WHR were determined according to the standard set by the Malaysian Clinical Practice Guidelines for the Management of Obesity ${ }^{22}$.

\section{Bioelectrical Impedance Analysis}

The body fat percentage and body fat mass were estimated by performing bioelectrical impedance analysis (BIA) using Tanita BC418 Body Composition Analyzer (Tanita Corporation, Tokyo, Japan) ${ }^{23}$. The instrument is portable, quick, relatively simple, and is used widely as a method to estimate body composition with a very strong correlation with the standard dual-energy X-ray absorptiometry ${ }^{24,25}$. Additionally, it generates reliable and reproducible results with very minimal intra- and inter-observer variation, along with $<1 \%$ variation upon repeat measurement ${ }^{26}$. To minimize error, all participants were asked to stand on the metal plate with bare feet and hold onto the metal grip of the device. The limbs were held out and ensured not to be in contact with other body segments during the procedure. Body composition analysis via BIA measures the fat, lean mass, and water content by measuring resistance (or impedance) as electrical signals pass through different tissue types of the body ${ }^{27}$.

\section{Blood Pressure and Capillary Blood Glucose Measurement}

The participants could rest for at least 5 minutes before blood pressure measurement using Omron ${ }^{\circ}$ SEM-1 (HEM-7051) electronic blood pressure device (Omron, Kyoto, Japan). The device has a sensitivity of $88.2 \%$ and specificity of $98.6 \%$ to detect hypertension ${ }^{28}$. An appropriate-sized cuff was applied to the middle part of the supported right arm in the sitting position while the device was ensured to be placed at the participants' heart level. If the first reading were high, the blood pressure would be measured again after the participant rested for another 10 minutes. The blood pressure reading was classified as either nonhypertensive ( $\leq 139 / 89 \mathrm{mmHg}$ ) or hypertensive $(\geq 140 / 90 \mathrm{mmHg}$ ) by referring to the criteria from the Malaysian Clinical Practice Guidelines for the Management of Hypertension ${ }^{29}$.

For capillary blood glucose measurement, index finger of the left hand was cleaned with 70\% isopropyl alcohol swab (Becton, Dickinson and Company, New Jersey, 
USA) and allowed to dry for few seconds. Upon pricking, the initial blood drop was wiped out with dry cotton. Subsequent blood was dropped into a glucose strip connected to the Accu-Chek ${ }^{\circ}$ Performa glucometer device (Roche Diagnostics, Basel, Switzerland). The readings of $\leq 7 \mathrm{mmol} / \mathrm{L}$ and $\geq 7.1 \mathrm{mmol} / \mathrm{L}$ were considered as normal and hyperglycemia, respectively, according to the Malaysian Clinical Practice Guideline for the Management of Type 2 Diabetes Mellitus ${ }^{30}$.

Since blood pressure and capillary blood glucose were measured using automated devices, we ensured that the participants were under standard conditions before and during the procedure. Only one trained person was responsible for the measurement of each parameter to reduce inter-observer variation.

\section{Statistical analysis}

The data were subjected to the Shapiro-Wilk test to identify the distribution type. Since the data was not normally distributed, each parameter was expressed in the median and interquartile range (IQR). Non-parametric Spearman $\rho$ correlation test was performed to look for correlation among those parameters. Strength of correlation was determined as poor $(0<r<0.3)$, fair $(0.3 \leq r<0.6)$, moderate $(0.6 \leq r<0.8)$, and very strong $(0.8 \leq r<1)^{31}$, while significance value was set at $p<0.05$. These tests were conducted using $\mathrm{IBM}^{\circ} \mathrm{SPSS}^{\circ}$ Statistics (version 23) software.

\section{RESULTS}

The participants in the health screening program had a median age of 39.50 years. For other parameters, their median and interquartile range are listed in Table 1.

Table 1 Characteristics of the participants expressed in median and interquartile range

\begin{tabular}{|c|c|c|c|}
\hline Parameters & Median & 1st centile & 3rd centile \\
\hline Age (years) & 39.50 & 23.00 & 45.25 \\
\hline Weight (kg) & 62.00 & 51.50 & 69.25 \\
\hline Height (cm) & 157.00 & 151.75 & 163.13 \\
\hline BMI (kg/m2) & 23.90 & 21.80 & 27.89 \\
\hline Waist circumference $(\mathrm{cm})$ & 90.50 & 82.00 & 97.00 \\
\hline Hip circumference (cm) & 100.00 & 95.50 & 106.00 \\
\hline Waist-to-hip ratio & 0.90 & 0.85 & 0.92 \\
\hline Body fat percentage (\%) & 31.40 & 24.23 & 34.10 \\
\hline Body fat mass (kg) & 18.95 & 14.10 & 24.05 \\
\hline Systolic blood pressure $(\mathrm{mmHg})$ & 124.00 & 111.50 & 135.25 \\
\hline Diastolic blood pressure $(\mathrm{mmHg})$ & 78.50 & 72.75 & 85.50 \\
\hline Capillary blood glucose (mmol/L) & 6.00 & 5.40 & 6.65 \\
\hline
\end{tabular}

As shown in Table 2, a quarter (28\%) of the participants were obese according to the BMI classification, with a median of 30.77 $\mathrm{kg} / \mathrm{m}^{2}$. Meanwhile, measurement of WC and WHR showed the contrary, whereby nearly two-thirds (78\% and $74 \%$, respectively) of them were classified as centrally obese with a median of $94.00 \mathrm{~cm}$ for WC and 0.90 for WHR.
On the other hand, $24 \%$ of the participants were hypertensive with median systolic blood pressure (SBP) of $150.50 \mathrm{mmHg}$ and $94.50 \mathrm{mmHg}$ for the diastolic blood pressure (DBP). Lastly, 20\% of the participants had hyperglycemia with a median capillary blood glucose reading of $8.60 \mathrm{mmol} / \mathrm{L}$. 
Prevalence of Obesity and Correlated Hypertension and Hyperglycaemia Status among Participants of a Health Screening Programme in Inanam Sub-district, Kota Kinabalu, Sabah, Malaysia

Table 2 Prevalence of obesity, hypertension, and hyperglycaemia among the health screening participants

\begin{tabular}{|l|l|l|l|l|}
\hline \multicolumn{2}{|l|}{ Parameters } & $\mathbf{n}$ & \% & Median (IQR) \\
\hline BMI $\left(\mathrm{kg} / \mathrm{m}^{2}\right)$ & Non-obese & 36 & 72 & $22.63(20.17-24.49)$ \\
& Obese & 14 & 28 & $30.77(28.30-32.93)$ \\
& Normal & 11 & 22 & $78.00(75.00-79.00)$ \\
WHR & Centrally obese & 39 & 78 & $94.00(87.00-100.00)$ \\
& Normal & 13 & 26 & $0.87(0.81-0.90)$ \\
BP (mmHg) & Centrally obese & 37 & 74 & $0.90(0.86-0.94)$ \\
& Non-hypertensive & 38 & 76 & SBP: $121.00(109.75-127.50)$ \\
& & & & DBP: $75.00(68.75-82.00)$ \\
Blood glucose & Hypertensive & 12 & 24 & SBP: $150.50(137.50-157.25)$ \\
$(\mathrm{mmol} / \mathrm{L})$ & Normal & 40 & 80 & DBP: $94.50(87.75-107.25)$ \\
& Hyperglycaemia & 10 & 20 & $8.60(7.73-9.25)$ \\
\hline
\end{tabular}

Abbreviations: BMI (body mass index), BP (blood pressure), DBP (diastolic blood pressure), Glu (capillary blood glucose), IQR (interquartile range), SBP (systolic blood pressure), WC (waist circumference), WHR (waist-to-hip ratio).

To look for correlation between all parameters, non-parametric Spearman's $\rho$ correlation coefficient test was performed (Table 3). Body fat percentage had a very strong correlation with body fat mass ( $r=$ $0.829, p=0.001)$, moderate correlation with $\mathrm{BMI}(r=0.656, p=0.001)$, and fair correlation with WC $(r=0.505, p=0.001)$. Additionally, body fat mass had a very strong correlation with BMI $(r=0.868, p=0.001)$, moderate correlation with WC $(r=0.761, p=0.001)$, as well as fair correlation with WHR $(r=0.358, p$ $=0.011)$. In the meantime, WC was found to have a moderate correlation with both $\mathrm{BMI}$ $(r=0.763, p=0.001)$ and WHR $(r=0.747, p=$ $0.001)$, along with a fair correlation with age $(r$ $=0.427, p=0.002)$. In contrast, WHR showed a fair correlation only with age $(r=0.329, p=$ $0.020)$ and BMI $(r=0.408, p=0.003)$. DBP had a very strong correlation with $\operatorname{SBP}(r=0.803, p$ $=0.001)$ together with a fair correlation with almost all other parameters including age $(r=$ $0.335, p=0.017)$, BMI $(r=0.390, p=0.005)$, WC $(r=0.467, p=0.001), \operatorname{WHR}(r=0.331, p=0.019)$, and body fat mass $(r=0.396, p=0.004)$. On the contrary, SBP had a fair correlation only with age $(r=0.359, p=0.011)$ and WC $(r=0.341, p$ $=0.015)$. 
Table 3 Spearman's $\rho$ correlation coefficient among age, BMI, WC, WHR, fat $\%$, fat mass, SBP, DBP, and glucose

\begin{tabular}{|c|c|c|c|c|c|c|c|c|c|c|}
\hline & & Age & BMI & WC & WHR & Fat $\%$ & $\begin{array}{l}\text { Fat } \\
\text { mass }\end{array}$ & SBP & DBP & Glu \\
\hline \multirow[t]{2}{*}{ Age } & $r$ & 1.000 & & & & & & & & \\
\hline & $p$-value & - & & & & & & & & \\
\hline \multirow[t]{2}{*}{ BMI } & $r$ & 0.201 & 1.000 & & & & & & & \\
\hline & $p$-value & 0.161 & - & & & & & & & \\
\hline \multirow[t]{2}{*}{ WC } & r & $0.427^{\dagger}$ & $0.763^{\dagger}$ & 1.000 & & & & & & \\
\hline & $p$-value & 0.002 & 0.001 & - & & & & & & \\
\hline \multirow[t]{2}{*}{ WHR } & $r$ & $0.329^{*}$ & $0.408^{\dagger}$ & $0.747^{\dagger}$ & 1.000 & & & & & \\
\hline & $p$-value & 0.020 & 0.003 & 0.001 & - & & & & & \\
\hline \multirow[t]{2}{*}{ Fat\% } & $r$ & 0.092 & $0.656^{+}$ & $0.505^{\dagger}$ & 0.244 & 1.000 & & & & \\
\hline & $p$-value & 0.524 & 0.001 & 0.001 & 0.087 & - & & & & \\
\hline \multirow[t]{2}{*}{ Fat mass } & $r$ & 0.167 & $0.868^{+}$ & $0.761^{+}$ & $0.358^{*}$ & $0.829^{+}$ & 1.000 & & & \\
\hline & $p$-value & 0.245 & 0.001 & 0.001 & 0.011 & 0.001 & - & & & \\
\hline \multirow[t]{2}{*}{ SBP } & $r$ & $0.359^{*}$ & 0.264 & $0.341^{*}$ & 0.222 & 0.024 & 0.260 & 1.000 & & \\
\hline & $p$-value & 0.011 & 0.064 & 0.015 & 0.121 & 0.871 & 0.068 & - & & \\
\hline \multirow[t]{2}{*}{ DBP } & $r$ & $0.335^{*}$ & $0.390^{+}$ & $0.467^{+}$ & $0.331^{*}$ & 0.171 & $0.396^{+}$ & $0.803^{+}$ & 1.000 & \\
\hline & $p$-value & 0.017 & 0.005 & 0.001 & 0.019 & 0.236 & 0.004 & 0.001 & - & \\
\hline \multirow[t]{2}{*}{ Glucose } & $r$ & 0.104 & 0.177 & 0.139 & -0.036 & 0.192 & 0.214 & 0.232 & 0.214 & 1.000 \\
\hline & $p$-value & 0.472 & 0.220 & 0.335 & 0.805 & 0.181 & 0.135 & 0.105 & 0.135 & - \\
\hline
\end{tabular}

"Correlation is significant with $p<0.05$ (2-tailed); ${ }^{\dagger}$ Correlation is significant with $p<0.01$ (2-tailed). Abbreviation: BMI (body mass index), DBP (diastolic blood pressure), Fat\% (body fat percentage), Glu (capillary blood glucose), SBP (systolic blood pressure), WC (waist circumference), WHR (waist-to-hip ratio).

\section{DISCUSSION}

This paper summarized the findings from a health screening programme conducted in a rural community of Inanam sub-district, Kota Kinabalu, Sabah, Malaysia. It marked the 4th edition of the "Jom Sihat Bah!" programme since its inception in 2016 which incorporated health awareness talks, health educational booths, blood donation drive, house visits, and donations to the underprivileged, as well as health screening initiatives ${ }^{32}$.

A total number of 50 participants in the health screening activities comprising both males and females were included in this study. Unlike our previous health-screening findings in a rural community of Kiulu, Tamparuli, Sabah, where the participants were mainly from the older-aged groups ${ }^{33}$, participants in the Inanam sub-district were mostly middleaged. Inanam was located less than $10 \mathrm{~km}$ from the Kota Kinabalu downtown as compared to Kiulu, which had almost quintupled the distance. Hence, the work opportunities might be highly available for the younger generations without the necessity to migrate to the urban area.

The prevalence of general obesity based on BMI was identical to the national prevalence $(28.0 \%$ and $30.6 \%$, respectively) but higher for the prevalence of central obesity based on WC $(78.0 \% \text { vs. } 48.6 \%)^{34}$. According to the WHR measurement, the prevalence of central obesity among the participants was also higher compared to the earlier reports by Ahmad and colleagues ( $74.0 \%$ vs. $44.8 \%)^{35}$. Since the Inanam sub-district was located in the vicinity of the outskirts of Kota Kinabalu, the community lifestyles might closely resemble the urban population than the rural ones. Generally, urbanites had lower physical activities compared to the rural-dwellers ${ }^{36}$ that 
might explain the higher prevalence of central obesity among the participants.

Although detection of general obesity via $\mathrm{BMI}$ and central obesity by WC and WHR yielded different results, all of them were directly correlated to the body fat compositions. Estimation of body fat mass and body fat percentage using BIA revealed that both parameters had a positive association with $\mathrm{BMI}$ and WC, with the former having additional positive association with WHR. Furthermore, positive associations were also seen among BMI, WC, and WHR. Traditionally, $\mathrm{BMI}$ alone was used to detect obesity as a risk factor for cardiometabolic diseases. However, it could not differentiate between subcutaneous and visceral adiposity, as well as the inability to discriminate between lean and adipose masses in general ${ }^{37,38}$. As a result, the classification of obesity might be inaccurate especially among individuals with larger muscle mass ${ }^{39}$. Therefore, a combination of all three parameters was often used as a holistic approach to assessing general obesity and central obesity during health screening activities ${ }^{40}$.

Hypertension prevalence among the participants of the health screening programme was almost similar to the national prevalence $(24.0 \% \text { and } 30.3 \% \text {, respectively })^{34}$. A prospective cohort study on Chinese adults found that central obesity predicted future hypertension independent of general obesity with a cumulative hypertension incidence of $25.9 \%$ over a period of ten years ${ }^{41}$. Consistently, our findings showed that both SBP and DBP had a positive correlation with central obesity. Thus, the high percentage of central obesity should raise concern among healthcare professionals regarding the risk of impending hypertension in this community. Therefore, a scheduled health screening program must be organized regularly for early diagnosis and commencement of treatment in order to achieve the desired blood pressure control and to prevent sequelae.
In this health screening programme, the hyperglycaemia prevalence among the participants was closely equivalent to the national prevalence $(20.0 \%$ and $17.5 \%$, respectively). Despite a robust positive association between hyperglycaemia and general obesity/central obesity ${ }^{42}$, our findings showed otherwise. This could be due to the small number of participants during the health screening programme. Besides, we only measured random capillary blood glucose to screen for hyperglycaemia which might be influenced by factors such as the time of last meal taken. The most accurate tests to check for hyperglycaemia as well as to diagnose diabetes mellitus are serum $\mathrm{HbA}_{1 c}$ and oral glucose tolerance test comprising of fasting and 2-hour postprandial blood glucose level measurement ${ }^{43}$ which we could not perform due to logistic limitations. However, similar to hypertension, the future risk for hyperglycaemia in this community should still be taken into consideration due to the higher percentage of central obesity found among the health screening participants.

\section{CONCLUSION}

The prevalence of general obesity, hypertension, and hyperglycaemia among the participants of the health screening programme in Inanam sub-district community was comparable to the national prevalence. However, central obesity was exceptionally higher than at the national level. It should raise concern among healthcare professionals regarding the future risk of hypertension and hyperglycaemia in this community.

\section{ACKNOWLEDGEMENTS}

We would like to thank the Department of Community and Family Medicine, Faculty of Medicine and Health Sciences (FMHS), Universiti Malaysia Sabah (UMS) for sponsoring the BIA device during the health 
screening program as well as students from the Medical Students Association (MEDSTAS) and Nursing Students Association (NUSA), UMS, for their volunteer works. Our gratitude is also extended to the organizing committee members, academicians, and staff from the Department of Biomedical Sciences and Therapeutics, FMHS, UMS, as well as medical professionals from the Pusat Rawatan Warga UMS for making the program successful.

\section{CONFLICT OF INTEREST}

The authors declare that they have no competing interests in publishing this article.

\section{REFERENCES}

1. Caballero B. (2007). The global epidemic of obesity: An overview. Epidemiol Rev 29 (1): $1-5$.

2. World Health Organization. (2019). Obesity and overweight: Fact sheet. http://www. who.int/mediacentre/factsheets/fs311/en/ (accessed on Jul 15, 2019).

3. Ghee LK. (2016). A review of adult obesity research in Malaysia. Med J Malaysia 71: 1 19.

4. World Health Organization. (2019). Global Health Observatory (GHO) data: prevalence of obesity among adults. https://www. who.int/gho/ncd/risk_factors/overweight_ obesity/obesity_adults/en/ (accessed on Jul 15, 2019).

5. Hill JO, Wyatt HR, Peters JC. (2012). Energy balance and obesity. Circulation 126 (1): 126 $-132$.

6. Samson SL, Garber AJ. (2014). Metabolic syndrome. Endocrinol Metab Clin North Am 43 (1): 1 - 23.

7. Landsberg L. (2001). Insulin-mediated sympathetic stimulation: role in the pathogenesis of obesity-related hypertension (or, how insulin affects blood pressure, and why). J Hypertens 19 (3): 523 528.

8. Pi-Sunyer X. (2009). The medical risks of obesity. Postgrad Med 121 (6): 21 - 33.
9. de Boer $\mathrm{H}$, Bangalore $\mathrm{S}$, Benetos $\mathrm{A}$ et al. (2017). Diabetes and hypertension: a position statement by the American Diabetes Association. Diabetes Care 40 (9): 1273 - 1284.

10. Fihaya FY, Sofiatin Y, Ong PA et al. (2015). Prevalence of hypertension and its complications in Jatinangor. J Hypertens 33: e35.

11. Funakoshi $\mathrm{M}$, Azami $\mathrm{Y}$, Matsumoto $\mathrm{H}$ et al. (2017). Socioeconomic status and type 2 diabetes complications among young adult patients in Japan. PLoS One 12 (4): e0176087.

12. Yu CP, Whynes DK, Sach TH. (2008). Equity in health care financing: the case of Malaysia. Int J Equity Health 7 (1): 15.

13. Alefan Q, Ibrahim MIM, Razak TA, Ayub A. (2009). Cost of treating hypertension in Malaysia. Asian J Pharm Clin Res 2 (1): 1 - 5.

14. Thomas S, Beh L, Nordin RB. (2011). Health care delivery in Malaysia: changes, challenges and champions. J Public Health Africa 2 (2): e23.

15. Ng JXT, Zaidun SM, Hong SC, Tahrin MFMA et al. (2010). Determining the attitudes of a rural community in Penang, Malaysia towards mental illness and communitybased psychiatric care. Internet J Third World Med 9 (1): 1 - 6.

16. Inche ZAS, Sutan R, Shamsuddin K. (2014). Prevalence and determinants of appropriate health seeking behaviour among known diabetics: results from a community-based survey. Adv Epidemiol 2014: Article ID 793286.

17. Harris H, Ooi YBH, Lee J-S, Matanjun P. (2019). Non-communicable diseases among low income adults in rural coastal communities in Eastern Sabah, Malaysia. BMC Public Health 19 (4): 554

18. Department of Statistics Malaysia. (2015). 2014 Sabah Statistics Yearbook. Department of Statistics Malaysia, Putrajaya, p. 13.

19. WHO Expert Consultation. (2004). Appropriate body-mass index for Asian populations and its implications for policy and intervention strategies. Lancet 363 (9403): 157 - 163.

20. Snijder MB, Dekker JM, Visser M et al. (2003). Associations of hip and thigh circumferences independent of waist circumference with the incidence of type 2 diabetes: the Hoorn Study. Am J Clin Nutr 77 (5): 1192 - 1197. 
21. Bacopoulou F, Efthymiou V, Landis $G$ et al. (2015). Waist circumference, waist-to-hip ratio and waist-to-height ratio reference percentiles for abdominal obesity among Greek adolescents. BMC Pediatr 15 (1): 50.

22. Academy of Medicine of Malaysia. (2004). Clinical practice guidelines on management of obesity. Ministry of Health Malaysia, Putrajaya, pp. 1 - 78.

23. Rebelo A, Brito J, Maia J et al. (2013). Anthropometric characteristics, physical fitness and technical performance of under-19 soccer players by competitive level and field position. Int J Sports Med 34: 312 317.

24. Rajkumari B, Akoijam BS, Akoijam JS, Longjam U. (2012). Assessment of body composition and body mass index of adolescent school children in Imphal-West district, Manipur. J Med Soc 26 (3): 184 - 188.

25. Chen KS, Chen YY, Wang CWet al. (2016). Comparison of standing posture bioelectrical impedance analysis with DXA for body composition in a large, healthy Chinese population. PLoS One 11 (7): e0160105.

26. Dehghan M, Merchant AT. (2008). Is bioelectrical impedance accurate for use in large epidemiological studies? Nutr J 7: 26.

27. Kyle UG, Bosaeus I, De Lorenzo AD et al. (2004). Bioelectrical impedance analysis-part I: review of principles and methods. Clin Nutr 23 (5): 1226 - 1243.

28. Vera-Cala LM, Orostegui $M$, Valencia-Angel LI et al. (2011). Accuracy of the Omron HEM705 CP for blood pressure measurement in large epidemiologic studies. Arq Bras Cardiol 96 (5): 393 - 398.

29. Malaysian Society of Hypertension. (2018). Clinical practice guidelines: management of hypertension, 5th edition. Ministry of Health Malaysia, Putrajaya, pp. 1 - 158.

30. Malaysian Endocrine and Metabolic Society. (2015). Clinical practice guidelines: management of type 2 diabetes mellitus, $5^{\text {th }}$ edition. Ministry of Health Malaysia, Putrajaya, pp. 1 - 129.

31. Akoglu H. (2018). User's guide to correlation coefficients. Turkish J Emerg Med 18 (3): 91 93.

32. Universiti Malaysia Sabah. (2019). FMHS UMS held community health service program "Jom Sihat Bah! 4.0". http://www.ums.edu. my/v5/ms/banner-link/7826-fmhs-umsheld-community-health-service-programjom-sihat-bah-4-0 (accessed on Jun 30, 2019).
33. Zarkasi KA, Ramli NZ, Mohamed K, Palasuberniam P, D' Souza UJA. (2018). Prevalence of obesity and metabolic derangement among the rural population of Kiulu district of Sabah, Malaysia: a health screening programme findings. Borneo J Med Sci 12 (2): 1 - 7.

34. Institute for Public Health. (2015). National Health \& Morbidity Survey 2015: Noncommunicable diseases, risk factors \& other health problems (volume II). Ministry of Health Malaysia, Kuala Lumpur, pp. 1 - 291.

35. Ahmad N, Adam SIM, Nawi AM et al. (2016). Abdominal obesity indicators: waist circumference or waist-to-hip ratio in Malaysian adults population. Int J Prev Med 7: 82.

36. Noor HI, Norazman MR, Diana M et al. (2016) Cardiovascular risk assessment between urban and rural population in Malaysia. Med J Malaysia 71 (6): 331 - 337.

37. Shah RV, Murthy VL, Abbasi SA et al. (2014). Visceral adiposity and the risk of metabolic syndrome across body mass index: the MESA Study. JACC Cardiovasc Imaging 7 (12): 1221 $-1235$.

38. Müller MJ, Braun W, Enderle J, Bosy-Westphal A. (2016). Beyond BMI: conceptual issues related to overweight and obese patients. Obes Facts 9 (3): 193 - 205.

39. Grier T, Canham-Chervak M, Sharp M, Jones $\mathrm{BH}$. (2015). Does body mass index misclassify physically active young men. Prev Med Reports 2: $483-487$.

40. Lam BCC, Koh GCH, Chen C et al. (2015). Comparison of body mass index (BMI), body adiposity index (BAI), waist circumference (WC), waist-to-hip ratio (WHR) and waistto-height ratio (WHtR) as predictors of cardiovascular disease risk factors in an adult population in Singapore. PLoS One 10 (4): e0122985.

41. Chuang SY, Chou P, Hsu PF et al. (2006). Presence and progression of abdominal obesity are predictors of future high blood pressure and hypertension. Am J Hypertens 19 (8): 788 - 795.

42. Chien LY, Liou YM, Chen JJ. (2004). Association between indices of obesity and fasting hyperglycemia in Taiwan. Int J Obes 28 (5): 690 - 696.

43. American Diabetes Association. (2017). Classification and diagnosis of diabetes. Diabetes Care 40: S11 - S24. 
